\title{
O professor no espelho: refletindo sobre a leitura de um relatório de estágio na graduação em Letras
}

\author{
The Teacher in the mirror: reflecting on a \\ student's internship report
}

Thomas Fairchild*

UFPA

RESUMO: Neste artigo defendo que um dos entraves centrais do ensino de Português é a dificuldade de o professor sustentar um discurso específico sobre o seu objeto de especialidade, o que põe em jogo sua própria condição profissional. Contra isso, venho pesquisando a formação de um "discurso profissional docente" através da análise da escrita de alunos de graduação em Letras. Apresento aqui a leitura de um relatório de estágio a partir do conceito de "imagem" proposto por Pêcheux (1969). Problematizo especificamente alguns processos de escrita que parecem favorecer a evasão do sujeito em relação à sua experiência mais do que a construção de conhecimento a partir dela. Nesse caso, em vez de se valer de instrumentos teóricos para analisar dados empíricos, o sujeito adere a explicações laterais ao seu objeto de análise, cujo motor é a ocultação de uma imagem de si. O resultado é uma elaboração que dificilmente se traduz em efeitos de formação, mas antes preserva o caráter leigo de seu discurso sobre o ensino.

PALAVRAS-CHAVE: discurso profissional docente, escrita na universidade, formação de professores; imaginário.

ABSTRACT: In this paper we defend that one of the main drawbacks in Portuguese first language teaching in Brazil is the teachers' difficulty to sustain a specific discourse about their object of expertise, which in turn puts their professional status at stake. In order to revert this, we have been studying how a "professional teacher's discourse" comes into being by analyzing pieces written by undergraduate students in Languages and Literature. We present here an analysis of an internship report based on the concept of "image" such as proposed by Pêcheux (1969). We discuss particularly writing procedures that favor the subject's evading her own experience more than using it to build new knowledge. In this case, instead of using theoretical instruments, the subject clings to explanations that stand beside her object of analysis, moved by the need to conceal an image she sustains of herself as a teacher. The result is a construction that can hardly push towards any educational improvement, but rather preserves the layman character of her discourse. KEYWORDS: professional teacher's discourse, undergraduate writing, teachers' education, imaginary.

*tmfairch@yahoo.com.br 


\section{Algumas Profissões e seus Discursos}

Um dos problemas mais sérios que vimos enfrentando no ensino de língua portuguesa está relacionado à dificuldade de o professor sustentar um discurso específico sobre o seu objeto de ensino, a língua. Ao contrário do que acontece com muitos outros profissionais, o professor de português vem encontrando cada vez mais problemas para situar, pela fala ou pela escrita, aquele que seria o seu campo de especialidade.

Basta nos valermos de uma comparação simples: ainda é muito comum que os textos produzidos na aula de língua retornem com comentários do tipo "muito bom", "melhore a organização das ideias" ou "explore a sua criatividade um pouco mais" - diagnósticos que se referem ao texto globalmente e não a qualquer parte específica, e se baseiam mais numa impressão intuitiva do que em fundamentos teóricos explícitos. Em contrapartida, se fôssemos ao médico e ele nos dissesse simplesmente "você está mal", "que catarro feio" ou "melhore seus hábitos alimentares", provavelmente nos sentiríamos mal atendidos. Isto porque sabemos o que esperar de um profissional dessa categoria: que ele acione uma série de procedimentos específicos de sua profissão (exame de sangue, pressão, radiografia, ultrassom etc.), amparados num conhecimento teórico que (acreditamos) ele domina e que o habilita a "ler" o significado dos nossos sintomas de uma maneira que nenhum outro profissional - inclusive nós mesmos - seria capaz.

Enfim, parece-nos que a confiança que muitas pessoas depositam na categoria médica, mas não na docente, está baseada em dois fatores essenciais: a) a capacidade do médico de sustentar um discurso profissional que distingue claramente o lugar de onde fala do de outros profissionais e do do paciente; e b) o fato de que esse discurso não se sustenta apenas numa aparência, ou seja, que numa porção suficiente dos casos a "leitura médica" do sintoma produz resultados perceptíveis também para aqueles que não pertencem à área (o alívio de um sintoma, a cura de uma doença).

Parece-me que o mesmo discurso precisa ser válido para o professor de língua portuguesa: também ele deve sustentar um discurso suficientemente específico para distingui-lo de outros profissionais (inclusive, os professores de outras áreas) e intervir sobre um campo específico (a escrita, o texto, o desempenho linguístico dos alunos) de maneira a produzir aí efeitos sensíveis, pelo menos na maior parte das vezes publicamente reconhecidos como satisfatórios. Nesse sentido, estamos de acordo com Riolfi et al. quando afirmam: 
Assim como o médico não se guia por suas opiniões pessoais, gostos e preconceitos para nortear a direção do tratamento dos pacientes, o professor não pode guiar-se exclusivamente pela percepção sensorial. O professor precisa, como profissional da educação, criar dispositivos com fundamentação teórica para que consiga vislumbrar, para além das aparências, a assimilação, as falhas, os pontos que precisam de reforço etc. (RIOLFI et al., 2008, p. 15).

Apesar disso, parece que um dos grandes problemas que vivenciamos hoje é a dificuldade de se determinar com clareza o que esperar do professor de Português, uma vez que boa parte dos elementos constitutivos de sua identidade profissional - o ensino da norma gramatical, o zelo ortográfico e estilístico, a exegese literária canônica etc. - foram abalados pelos debates epistemológicos que remodelaram o terreno da disciplina nos anos 1980 . Como já vem sendo muito apontado, a conjuntura de dois fatores parece ter instaurado este impasse: o fato de as perspectivas sócio-interacionistas terem adquirido caráter oficial, inicialmente em propostas curriculares de alguns Estados (Paraná, Mato Grosso, São Paulo) e mais recentemente nos PCN, de modo que se criou uma pressão para que o professor mostre adesão a esse viés teórico; e o fato de esse processo não ter sido acompanhado pela implantação de dispositivos de formação capazes de garantir que essa adesão se manifeste em um plano mais profundo que o da simples reprodução de fragmentos discursivos ou termos isolados.

Como professor da graduação em Letras, venho me dedicando à investigação de alguns dos processos relacionados a esta segunda circunstância ${ }^{1}$, isto é, a dificuldade de formar professores que efetivamente lidem com as propostas oficiais em um plano epistemológico. Venho me indagando centralmente sobre duas questôes: a) de que forma o discurso de um aluno se modifica ao longo e por conta de uma graduação em Letras; e b) de que forma essas modificaçõoes constituem (ou não) o que poderíamos chamar de um discurso profissional docente. Tenho partido do pressuposto de que esses deslocamentos discursivos consistem em uma escrita, de modo que procuro analisar, nos textos produzidos por alunos de graduação, vestígios dos movimentos aos quais se poderia atribuir o sentido de uma formação em Letras

\footnotetext{
${ }^{1}$ Atualmente, esses esforços estão sistematizados no projeto de pesquisa "O sujeito na escrita universitária: indícios de subjetivação e construção de um discurso profissional docente".
} 
ou, pelo contrário, os processos que permitem a assunção de um discurso apenas superficialmente (logo diremos: imaginariamente) diferenciado do ponto de vista leigo, e se tanto aparentemente profissional.

Dentro das linhas dessa investigação, discutirei neste artigo um momento específico da formação do professor: o relatório de estágio. Considero que o estágio é uma passagem de fundamental importância na formação, pois se trata do momento em que o estudante põe o corpo à prova $\mathrm{e}$ precisa discursivizar uma série de experiências que o atingem de maneiras nem sempre facilmente dizíveis. Vale ressaltar que esta discursivização passa tanto pela produção de análises mais objetivas de dados empíricos quanto pela busca de maneiras de lidar com o que chamarei de um corpo inefável, isto é, aquele leque de sensações causadas pela docência que, ainda que normalmente não associadas aos aspectos técnicos da profissão, determinam com muita força uma maneira de portar-se profissionalmente. Um corpo que se retesa ao ser observado, ou cresce muito diante do auditório; um corpo que fala rápido demais, ou talvez alto de mais; um corpo que ri à socapa, ou se arrepia em antecipação da aula, ou parece preferir certas posições a outras mesmo quando um pouco incômodas: enfim, parece que há algo no corpo do professor que, talvez mais do que em outras profissões (não todas), ultrapassa o terreno de uma formação técnica e exige um outro tipo de reflexão formativa, intimamente ligada à maneira como esse professor se constitui enquanto sujeito. Uma concepção de formação sensível a essa dimensão da docência precisaria procurar frestas pelas quais esse corpo indizível possa chegar a se tornar discurso.

A análise seguinte enquadra-se na busca de maneiras de lidar com a problemática do sujeito na formação de professores. Trata-se, acima de tudo, de um ensaio de leitura: buscarei situar os diferentes movimentos discursivos que, num relatório de estágio, marcam a posição de um sujeito dividido, discutindo o fato de que esses movimentos não são igualmente relevantes em termos de uma formação em Letras. Para esta leitura, partirei do conceito de "imagem" proposto por Pêcheux e lhe acrescentarei alguns comentários sobre a noção de "imaginário" em Lacan; em seguida, buscarei fazer o que chamava há pouco de uma "leitura médica" do texto. ${ }^{2}$

\footnotetext{
${ }^{2}$ Impossível fazer essa metáfora sem remeter ao texto de Ginsburg (1989), no qual ele esclarece como não é coincidência que o olhar do linguista guarde semelhanças com o do médico.
} 


\section{As Condições de Produção da Escrita de um Relatório de Estágio}

Althusser (1980) caracteriza as condiçōes de produção como o conjunto das relaçôes de produção - que, no capitalismo, são necessariamente relaçõos de exploração - e das forças produtivas - os meios de produção e a força de trabalho. $\mathrm{O}$ conceito de condições de produção da linguagem elaborado por Pêcheux transpõe à linguística a mesma ideia de uma relação de forças (entre sujeitos e não mais entre classes) na base da produção (agora de um discurso). Essas imagens determinam as posiçôes relativas dos interlocutores e correspondem ao modo como um sujeito se coloca em relação a si mesmo, ao outro e ao seu referente - dizem respeito, portanto, às relações de força implícitas no ato de interação verbal.

De acordo com Pêcheux, as condições de produção do discurso, conjugadas por sua vez a um sistema linguistico, criam uma matriz que orienta as escolhas do sujeito dentro desse sistema linguístico e determinam seu discurso. A isso Pêcheux nomeou processo de produção da linguagem, que pode ser traduzido por perguntas hipotéticas inerentes a todo enunciado: quem sou eu para lhe falar assim?, quem é você para que eu the fale assim?, o que é isso de que the vou falar? Essas três perguntas correspondem, respectivamente, a três imagens que concorrem na determinação do discurso de um enunciador: a imagem que o sujeito em uma posição $A$ (o enunciador) tem do sujeito em $A$, ou $\left[I_{A}(A)\right]$; a imagem que o sujeito em $A$ tem do sujeito em $B$ (o enunciatário), ou $\left[\mathrm{I}_{\mathrm{A}}(\mathrm{B})\right]$; por fim, a imagem que o sujeito em A tem do referente, ou $\left[I_{A}(R)\right]$. Pêcheux propóe que se leve em conta, ainda, um segundo grau imaginário, correspondente às imagens das imagens do outro. Teremos então as seguintes perguntas: quem eu penso que você pensa que sou para lhe falar assim? $\left\{\mathrm{I}_{\mathrm{A}}\left[\mathrm{I}_{\mathrm{B}}(\mathrm{A})\right]\right\}$, quem eu penso que vocêpensa que é para lhe falar assim? $\left\{\mathrm{I}_{\mathrm{A}}\left[\mathrm{I}_{\mathrm{B}}(\mathrm{B})\right]\right\}$, o que eu penso que vocêpensa sobre isso? $\left\{\mathrm{I}_{\mathrm{A}}\left[\mathrm{I}_{\mathrm{B}}(\mathrm{R})\right]\right\}$.

A essas considerações sobre as "formações imaginárias" é preciso acrescentar uma premissa proveniente da Psicanálise: que o sujeito pode estar relacionado a essas imagens de duas formas distintas - conhecendo-as, e logo movimentando-as propositalmente; ou desconhecendo-as, e portanto sendo movimentado por elas. Uma das teses centrais da Psicanálise, com efeito, é a da existência de um inconsciente, demarcado por um efeito que, pelo menos a partir de Lacan, podemos entender como sendo "linguageiro": o recalcamento. Disso decorre o seguinte: num dado discurso, o sujeito precisa ser compreendido como dividido, minimamente, entre aquelas imagens que agencia explicitamente (aquilo que "diz sobre si", as imagens do enunciado) e aquelas que, sendo 
sempre assumidas de maneira implícita, lhe dão um lugar desde onde dizer (aquilo que "diz de si", as imagens da enunciação).

Esse quadro teórico nos impõe uma reflexão sobre as condições de produção do tipo de dado a ser analisado aqui. Sabemos que um relatório de estágio pode ser escrito tendo-se em mente diversos objetivos ou concepções sobre o próprio relatório; a maneira como relator e leitor se relacionam no interior de uma formação imaginária depende muito de quais objetivos ou concepçóes eles assumem prioritariamente.

Uma forma de se pensar o relatório é como documento que serve para informar um professor do que ocorreu durante as aulas de estágio. Como dificilmente o professor pode acompanhar todos os estagiários, o registro escrito é uma maneira de garantir que ele se mantenha a par do trabalho realizado e possa fazer comentários e sugestôes, indicar leituras ou avaliar o desempenho do aluno. De maneira semelhante, mas não idêntica, pode-se pensar o relatório como uma prestação de contas: é preciso narrar o que ocorreu não somente para informar mas também para provar que o estágio foi cumprido a contento.

Uma terceira forma de pensar o relatório, talvez menos evidente, é como documento argumentativo. Uma vez que se atribui uma nota ao relatório, é presumível que o estagiário o escreva com o propósito mais ou menos velado de convencer seu professor da suficiência e qualidade de seu trabalho. Buscase justificar as escolhas tomadas no planejamento das aulas e demonstrar o sucesso de sua realização, algumas vezes com base em afirmaçôes sobre a satisfação de alunos e professores. Que argumentos o aluno agencia e que argumentos o supervisor de estágio aceita dependem das concepçóes de linguagem, escola e docência de cada um, e são questões que poderiam ser colocadas em debate com mais frequência.

Enfim, uma última forma de se pensar o relatório é como trabalho de organização de uma experiência. Isto implica escolhas de diversas ordens - por exemplo, sobre o que é relevante e o que é irrelevante relatar, quanto convém escrever, que palavras melhor designam determinado fato etc. Essas escolhas estão presentes na formulação de qualquer enunciado, mas são objeto pertinente na avaliação de um relatório quando se trata, por exemplo, de escolher entre termos como "expressar" ou "comunicar", "justificativa” ou "argumento", "frase" ou "sintagma" etc. Não é preciso lembrar que a maneira como o estudante se porta em relação a essas escolhas (se elas chegam a se constituir para ele) depende tanto de seu conhecimento teórico quanto da imagem que ele tem daquele para quem ele escreve o texto. 
Em suma, podemos dizer que estas são as quatro principais imagens do que vem a ser um relatório de estágio, expressas pela fórmula $\left\{\mathrm{I}_{\mathrm{A}}(\mathrm{R}) / \mathrm{I}_{\mathrm{A}}\left[\mathrm{I}_{\mathrm{B}}(\mathrm{R})\right]\right\}$ :

- o relatório é uma exposição de experiências;

- o relatório é uma prestação de contas;

- o relatório é um documento argumentativo;

- o relatório é um trabalho de organização do conhecimento.

Essas prerrogativas compóem uma cena básica na qual supomos que se produzem os relatórios de estágio, mas vale lembrar que elas podem aparecer no texto tanto como imagens "ditas", abertamente declaradas pelo autor, quanto como imagens "constitutivas", ligadas ao lugar em que ele se coloca ao escrever ou o leitor se coloca ao ler. Não é necessário que essas duas séries de imagens coincidam - talvez seja uma regra que elas sempre se desencontrem em alguma medida. Procurar alternativas de ensino que problematizem o sujeito implica buscar esses desencontros por meio de uma leitura que se desvincule daquelas imagens de cunho mais explícito, inscritas no enunciado, para lidar com as imagens que regem a enunciação.

\section{Leitura de um Relatório de Estágio}

Todos os trechos a serem analisados a seguir provêm de um relatório de estágio escrito por uma aluna do quarto ano de Letras em 2006. A escolha desse relatório pede algumas justificativas: em primeiro lugar, trata-se de um texto bem escrito, produzido por uma aluna cujos conhecimentos teóricos já haviam ficado patentes em outros trabalhos da graduação. Apesar disso, é um texto em que se pode apontar com certa clareza o desencaixe entre as posições construídas no plano declarativo e aquelas que se mostram mais ligadas a uma posição subjetiva. Consiste, portanto, em um texto sui generis na produção dessa aluna, surpreendente por deixar de apresentar as qualidades demonstradas em outras ocasiōes - de modo que nos leva a supor que há fatores para além da técnica envolvidos na qualidade de um trabalho.

O que deterá nossa atenção aqui é o desenvolvimento de uma linha argumentativa conduzida pela aluna com certa habilidade, mas que pouco contribui para a qualidade do relatório porque gira em torno da necessidade de manter implícita uma imagem à qual o sujeito está ligado. Problematizaremos o fato de que, por estar fora do alcance das palavras, essa imagem impede o sujeito de incluir em seu discurso o que quer que ameace movê-la - sejam os 
dados da realidade escolar, sejam os discursos dos seus possíveis interlocutores (alunos, professores, autores da bibliografia da área etc).

A exposição seguinte está dividida em três partes, nas quais enfatizo a construção de determinadas imagens e a maneira como elas se movimentam a fim de preservar o caráter implícito daquela outra.

\section{Problemas de Força Maior}

O texto inicia-se definindo a si mesmo como um documento informativo, uma exposição de experiências:

(1) Este relatório de estágio supervisionado em língua portuguesa tem por objetivo apresentar informaç̧oes à cerca dos estágios de atuação que, por sua vez são de extrema importância para a preparação dos futuros profissionais de língua portuguesa. Por esta razão, todo graduando deve cumprir com uma carga horária de estágios de observação e atuação estipulada pelo seu curso.

Pouco surpreende até aqui. Sabemos que nenhum texto produzido entre aluno e professor é puramente informativo, mas a colocação da aluna pode ser uma forma de iniciar uma negociação com o seu destinatário - trata-se consensuar a natureza da interlocução (vamos acordar porque estou escrevendo e porque você está lendo), ou, ainda, de calibrar um certo grau de cordialidade, uma espécie de diplomacia da escrita. Esta última perspectiva é mais interessante, porque mostra que seria arriscado, por exemplo, iniciar um relatório afirmando que ele visa comprovar a realização dos estágios - isto significaria imputar ao professor uma suspeita que poderia não lhe cair bem, além do que suporia apresentar o texto como um argumento mais forte do que aqueles aos quais a atual opiniáo do professor estaria presa (se você pensa que burlei os estágios, verá que se enganou: eis a prova).

Sob esse tipo de polidez frequentemente há imagens mais significativas. Diremos que a mais importante delas, no caso dessa aluna, é a do professor enquanto avaliador propenso a reprová-la. Esse papel prefigura-se aqui na menção à carga horária dos estágios, que a princípio parece redundante, uma vez que se trata de um dado óbvio tanto para o escritor quanto para o leitor. Devemos supor que ao dizer isso a estagiária não visa à informatividade de seu texto; o que faz, de fato, é remeter o leitor a um outro discurso: parece que a aluna faz lembrar as dificuldades que encontrara para conciliar o estágio com o emprego e os recorrentes remanejos de horário que haviam sido necessários 
no decurso do semestre. Está aí uma reclamação-clichê, mas o que nos interessa é pensar nos efeitos discursivos visados com esse tipo de construção. Mencionar a carga horária dos estágios, com efeito, não é apenas uma maneira de preencher espaço mas também uma forma de convocar ao discurso, sem dizê-lo, uma posição que será sustentada no restante do texto: não fiz melhor porque as circunstâncias me impediram.

Logo mais isso ganhará corpo. É o que ocorre no trecho abaixo, retirado de uma das primeiras entradas do relatório:

(2) Hoje deu uma tempestade enorme na cidade, a chuva não parava de cair. Por pouco não fui dar aula, pois pensei na possibilidade de nenhum aluno comparecer ao colégio. Como a maioria mora perto do colégio, decidi enfrentar a chuva e ir até o colégio.

Quando cheguei, tudo estava deserto e frio. Para começar nem a secretária estava por lá, mas entrei e fui direto para a sala dos professores. Lá encontrei a diretora e duas professoras que disseram que era meio difícil todos os alunos comparecer, mas que se viesse um ou dois, daríamos aula normal porque mais para frente teria muitos feriados. (...)

Este tipo de argumentação requer alguns comentários pontuais. $\mathrm{O}$ primeiro talvez seja o de que, embora a estagiária relate ter feito o mínimo esperado (comparecer à escola no dia combinado), ela apresenta em primeiro lugar um fato em relação ao qual seu comparecimento torna-se uma concessão - mesmo com tempo ruim, e apesar do risco de não haver alunos, "decidi enfrentar a chuva". O fato de que a ida à escola seja apresentada como um enfrentamento sugere um desejo de não ir que já havia se formulado na ambiguidade da frase "por pouco não fui dar aula" (seria diferente escrever, por exemplo: consegui dar aula). Não é demais frisar: isso pouco tem a ver com o problema da veracidade. Se a escola funciona ou não nos dias de chuva, isso interessa menos no seu valor documental do que no seu valor argumentativo. ${ }^{3}$ É nesse plano que poderemos notar que o resultado de um ato realizado contra a vontade é uma espécie de vingança sobre o agente da proibição - com efeito, no parágrafo seguinte a escola é descrita como um local "deserto e frio" e os seus funcionários, professores e alunos, como descomprometidos.

\footnotetext{
${ }^{3}$ Mas é claro que o dado em si não é desprezível enquanto denúncia de uma efetiva situação de precariedade.
} 
Essa saga meteorológica parece ter a função de negociar o abrandamento de uma possivel avaliação negativa do professor. É provável que esse seja um princípio aplicável a todo escrito que se dirige a um professor, mas o mais importante não é o receio de ser mal avaliada em si. Notemos que embora a estagiária repute ao professor, quase inequivocamente, uma avaliação negativa, ela dá poucos sinais de ter consciência (ou buscar ter consciência) de quais aspectos de sua atuação poderiam suscitar essa crítica do professor. Situar os motivos específicos do desconforto em relação à avaliação do professor talvez fosse o primeiro passo para obter uma avaliação melhor.

Outro ponto a considerar é que a tentativa de esquivar-se de uma crítica aciona uma imagem $I_{A}(R)$, em que essa crítica é redirecionada à escola: com efeito, parece que é unicamente a escola (não a estagiária) que não funciona em dias de chuva. O sucesso desse argumento depende em boa medida da suposição de que o seu leitor aceitará essa imagem $\left\{\mathrm{I}_{A}\left[\mathrm{I}_{B}(\mathrm{R})\right]=\mathrm{I}_{\mathrm{A}}(\mathrm{R})\right\}$. O que nos resta atestar é que, para além de certa ginga discursiva, realiza-se aí um discurso no qual a reprodução de uma imagem negativa da escola fica estreitamente relacionada ao dizer do professor.

Eis um exemplo semelhante:

(3) Cheguei na cidade bem cedo para ir antes numa farmácia e só depois entrar numa sala de aula. Hoje eu estava mal de saúde, passei um dia antes de cama por causa de uma gripe muito forte e começo de anemia. Eu não estava podendo comigo, mas fiz o possível para não faltar ao meu compromisso (...).

Como se vê, a chuva cobrou seu pedágio. Se a tentativa de abrandar o julgamento do professor é uma técnica comum, os pontos onde essa técnica se aplica talvez nos revelem algo da própria cultura universitária, pois indicam o que a aluna considera que seu professor possa considerar uma falha ou justificativa para essa falha $\left\{\mathrm{I}_{\mathrm{A}}\left[\mathrm{I}_{\mathrm{B}}(\mathrm{R})\right]\right\}$, sendo $\mathrm{R}=$ escola, professor, docência etc. No presente caso, tudo gira em torno de demonstrar como a dedicação da aluna aos estágios teria sido posta à prova pelas intempéries e suas consequências sobre a saúde. Assim se projeta uma imagem do bom professor como professor dedicado, perseverante, mas sobre isso restaria indagar: para ser professor basta demonstrar dedicação, perseverança? Outra imagem agregada a esses enunciados, de tom mais sombrio, é a de que, no caso particular da profissão docente, sofrer seria algum tipo de mérito, de modo que mostrar sofrimento parece ser entendido como forma viável de se preencher um relatório no qual seria de se esperar, em princípio, um discurso profissional. 
Enfim: o grande problema deste tipo de argumentação é o fato de que ela se fia na necessidade de reproduzir uma imagem da escola e da própria profissão docente marcada pelo suplício, pela privação, pelo improviso, pela boavontade acima da competência, do planejamento ou da ação transformadora. Tem-se aí, mais do que uma tentativa de safar-se de uma nota ruim, uma forma de organizar o conhecimento empirico, e eis um dos motivos para se refletir sobre a leitura de relatórios: pois se trata de um conhecimento que leva a reconhecer na escola apenas aquilo que ela apresenta como empecilho e desencoraja a tentativa de superar problemas possivelmente reais - já que é exatamente deles que depende a imagem de professor sustentada no discurso.

\section{Quem Você Pensa que É?}

A certa altura do semestre, um dos motivos de inquietação da estagiária passou a ser o comparecimento do supervisor às aulas que ela ministrava na escola. A presença do professor, estipulada pelo regulamento de estágio da universidade, tem sobre a estagiária um efeito pouco surpreendente: aumentar seu desconforto e nervosismo. Se isso é, mais uma vez, algo bastante previsível na situação de estágio, vale a pena notar que esse desconforto surge aqui de maneira particular:

(4) $\mathrm{Na}$ aula de hoje meu professor de estágio resolveu fazer sua primeira avaliação na sala em que eu estava atuando, na realidade era a primeira avaliação que ele fazia de mim. Só eu sei como essa ideia de ser avaliada me incomodava e, além disso, o que mais me preocupava era que fazia pouco tempo que esse professor havia assumido a minha turma e dessa forma esse era o primeiro contato imediato com cada acadêmico, o que implicava numa falta de conhecimento sobre ambas as partes. Então, se eu não tivesse bem nesse dia com certeza ele iria pensar que não sou uma pessoa capaz de fazer um bom trabalho. Se fosse a professora anterior que trabalhou as aulas de estágio durante um ano e meio, seria totalmente diferente, pois a mesma conhecia a capacidade de cada acadêmico e se fosse chamar a atenção ou julgar, seria pelo fato desse conhecimento.

A estagiária continua antecipando uma possível avaliação negativa por parte do professor e, precavendo-se de sua possível reprovação, adia a descrição das atividades realizadas no dia com esse intróito. Ainda se trata de elencar fatos que amenizem possíveis falhas, mas agora surge um segundo ponto de incidência, a capacidade de avaliação do supervisor. 
No trecho acima, a estagiária inicia a entrada procurando demonstrar que estava nervosa, de modo que qualquer crítica ao seu desempenho ficaria contrabalançada por essa condição. Mas é preciso notar que a escolha do verbo "resolveu", na primeira linha, atribui a causa do seu nervosismo ao próprio supervisor, já que sugere que sua visita poderia ter sido uma surpresa. A seguir, a estagiária levanta o pouco tempo de contato do supervisor com os acadêmicos ("falta de conhecimento") como empecilho à sua avaliação. A ideia de que um certo grau de proximidade entre o avaliado e o avaliador seja parâmetro para essa avaliação talvez seja o ponto mais interessante a ser discutido com base nesse excerto, porque aponta para a ideia de uma prática escolar pautada em relações de cumplicidade, e não de competência. Em todo caso, notemos que o argumento expresso nas três últimas linhas acrescenta a isso outra dimensão, também muito sensível, porque toca no problema de se dirigir uma crítica a uma instância hierárquica superior. A estagiária, de fato, evita contestar abertamente a autoridade do supervisor, contrapondo-a à de um par de condição hierárquica igual: a professora anteriormente responsável pela disciplina ("se fosse a professora anterior... seria totalmente diferente...").

A sequência do trecho que lemos acima é a seguinte:

(5) Tentei me acalmar e fui para a sala de aula acompanhada pelo professor. Entramos na sala de aula que se encontrava numa bagunça total. Tive que acalmar a turma, pedir para que cada um procurasse $o$ seu lugar e ficasse acomodado. Depois de algum tempo consegui fazer com que se acalmassem, então, apresentei o professor que logo foi para a última carteira para que eu pudesse iniciar a aula. Como já havíamos trabalhado em aulas anteriores o discurso indireto eu dei o comando para que o alunos fizessem uma produção textual que justamente era o meu alvo para possível avaliação. Tive que voltar algumas vezes para a explicação do discurso porque alguns alunos não estavam conseguindo distinguir um discurso do outro. Alguns não tinham a mínima ideia de como começar o texto e por isso mesmo, ficavam atrapalhando os colegas que já haviam começado a escrita. Enquanto faziam o texto, eu passava olhando como estava o texto e até dando ideias do que fazer no texto. Até o meu professor deu algumas dicas. Nem bem os alunos entregaram os textos o sinal bateu para o intervalo. Depois tive uma conversa com o meu professor de estágio sobre as minhas atividades.

Apesar de outros aspectos que mereceriam alguma consideração, como a forma um tanto vaga como a estagiária descreve o desenrolar de sua aula, o que nos deterá sobre essa passagem é o uso da palavra "acalmar". Aí se realiza 
um jogo sutil, mas suficiente para sugerir uma articulação: ao repetir o verbo "acalmar", a estagiária identifica sua condição ("tentei me acalmar") à condição dos alunos de sua sala ("tive que acalmar a turma"). Essa identificação parece ter um prolongamento: a expectativa de avaliação que a estagiária atribuía ao supervisor no parágrafo precedente parece estar relacionada ao papel que ela mesma atribui a si enquanto professora - "era o meu alvo para possível avaliação". É uma hipótese, portanto, que a formação imaginária subjacente ao discurso desse sujeito se caracteriza por um espelhamento entre a imagem que essa estagiária sustém de seus alunos e a imagem que ela supóe que o seu professor sustenha dela enquanto aluna.

Se assim for, começa a surgir um núcleo de contradição no interior dessa escrita. Dispúnhamos, a princípio, de uma imagem que ela construía de si enquanto espécie de personagem heróica, que paga com a própria saúde para cumprir os compromissos, e dispomos agora de um forte indício de que a imagem que a estagiária mantém de seus alunos está de alguma maneira identificada a uma imagem de si. Resta apenas notar que essas duas imagens, tal como se manifestam explicitamente no discurso, não correspondem: aos alunos, pelo contrário, ela atribui predicados como "uma bagunça total", "alguns não tinham a mínima ideia...", ou ainda, por metonímia, "tudo estava deserto e frio". Disso se pode tirar a hipótese de que está em jogo uma imagem interditada, em recalque, cuja explicitação traria como custo algum tipo de sofrimento ao sujeito, e da qual a escrita desse relatório é, em grande medida, o sintoma. ${ }^{4}$

\section{Mais um Dia de Estágio, Mais uma Aula a Preparar...}

Ousemos dizer que no cerne do processo de produção deste texto está um sujeito cuja prioridade é manter oculta uma imagem de si colocada em movimento pelas atividades de estágio, cuja aparição exporia um desejo que não encontra assento nas atividades que a estagiária vinha então realizando. Para manter implícita essa imagem, que a impede de realizar um trabalho mais bem engendrado, ela necessita rodear-se de obstáculos e adversidades às quais possa atribuir - imaginariamente - o mau sucesso que ela mesma está empenhada em garantir.

${ }^{4}$ Embora, talvez, não o único - se acreditarmos que a escrita, ainda que opaca, preserva uma possibilidade de representação, o relatório está bem provido de descriçōes de mal-estar físico e adoecimento. 
Por que um sujeito se dedicaria à tarefa de desfazer ardilosamente aquilo que se dedica a realizar? A estagiária prossegue relatando o andamento de suas aulas. Segue outra entrada do relatório:

(6) Novamente o professor de estágio e a professora regente vão assistir à minha aula. Dessa vez, estou um pouco mais calma, mas não sei como vai ser o comportamento dos alunos.

Entrei na sala, a turma por incrível que pareça estava calma esperando para o início da aula. Enquanto eu explicava o conteúdo de gramática fazia questão de olhar fixamente para todos aqueles que me encaravam, principalmente para os professores que faziam a descrição não sei se era do conteúdo ou do meu desempenho, mas isso era o de menos. Estava um pouco pesado o conteúdo e isso exigia muito de mim mesma porque a turma não estava colaborando. (...) Por fim, o sinal rompeu aquele ambiente e estava na hora de ir embora. Na saída fui conversando com o professor a respeito dessa aula. Mais uma vez ele não disse nada do meu desempenho, apenas comentou que a turma estava mais tranquila durante esse tempo por motivo de ser a última aula ou porque o conteúdo exigia mais dos alunos.

Nossa hipótese passou a ser a de que há uma identificação entre uma imagem de si implícita e a imagem explícita que esse sujeito constrói dos alunos. Se essa hipótese for sustentável, a afirmação inicial desse trecho, "não sei como vai ser o comportamento dos alunos", pode ser alusiva à forma como a estagiária se sente em relação ao seu próprio comportamento, já que precisa de um apoio na indisciplina da turma para sustentar a imagem explícita que tem de si $\left[\mathrm{I}_{\mathrm{A}}(\mathrm{A})\right]$ como uma espécie de vítima das circunstâncias. De fato, algumas linhas abaixo, ela afirma que "a turma não estava colaborando", ainda que a primeira impressão fosse justamente do bom comportamento dos alunos. $\mathrm{O}$ receio de não saber "como vai ser o comportamento dos alunos", dessa forma, paira sobre uma dúvida que vem se tornando central para a estagiária: não sei o que farei se não puder contar com a bagunça dos alunos para justificar meu comportamento.

Ao que tudo indica, esse receio é acompanhado pelo destacamento de um novo motivo de incômodo: o olhar. É portanto uma problemática da imagem que se coloca agora de forma explícita, já que a indagação da estagiária é sobre o que veem aqueles que a observam. Mais uma vez, a postura assumida por ela é de enfrentamento: "fazia questão de olhar fixamente para todos aqueles que me encaravam". Isso pode sugerir uma certa didática do corpo, uma afirmação de segurança, mas também reforça nossa suposição de que há nessa 
escrita um jogo de espelhos: não se trata de responder ao olhar propriamente dito e suas demandas, mas de refleti-lo de volta. O problema se mostra, dessa forma, como estando relacionado à falta uma imagem: o que veem em mim aqueles que me fitam?

Está aberta uma lacuna no lugar de $\mathrm{I}_{\mathrm{A}}\left[\mathrm{I}_{\mathrm{B}}(\mathrm{A})\right]$ : os professores faziam anotações "não sei se era do conteúdo ou do meu desempenho". A afirmação de que "isso era o de menos" parece confirmar essa lacuna pela denegação, visto que é justamente desses comentários que se ocupam os pensamentos da estagiária durante a aula. Um pouco mais adiante, de fato, ela relata a tentativa de obter um retorno do professor de estágio, bem como alguma frustração com o fato de este não lhe responder como esperava: "mais uma vez ele não disse nada do meu desempenho". Talvez haja algo generalizável nessa situação: na presença do supervisor, a aluna não demanda uma orientação, não elabora questões específicas sobre suas dificuldades - o que demanda é a resposta para sua própria angústia, na forma da devolução de uma imagem. Diremos: uma imagem de si, justamente aquela que lhe falta porque está em recalque.

Isso tem uma implicação fundamental: a de que o sujeito reputa ao outro a imagem de si que mantém interditada. A decepção com a ausência de um comentário do professor, nesse sentido, sugere que o sujeito precisa de um comentário crítico que corresponda às críticas que faria de si mesmo. Esse comentário, de fato, é preciso para arrematar o conjunto dos argumentos que sustentam o recalcamento da imagem que o representa: "o que mais me preocupava era que fazia pouco tempo que esse professor havia assumido a minha turma". Em outras palavras: um comentário negativo do professor permitiria retirá-lo do lugar de autoridade simbólica, no qual a estagiária o coloca pelo próprio olhar, para enquadrá-lo numa imagem previamente inoculada, a de um professor de quem só se poderia esperar críticas infundadas. ${ }^{5}$

Em todo caso, como essa crítica permanece sem confirmação, é de se supor que o sujeito encontre a si mesmo ameaçado pela possibilidade de não encontrar um suporte para o seu próprio discurso. Isso pode explicar, em parte, a multiplicação dos sinais de desconforto e impaciência da estagiária com as próprias aulas:

\footnotetext{
${ }^{5}$ Um exemplo prototípico desse processo de anulação de argumento é o da suposta manchete que afirma: Papa condena o uso da camisinha. Remeter uma determinada posição a alguém de quem só se poderia esperar essa posição é, de fato, um dos meios de que dispomos de advogar contra essa posição.
} 
(7) Mais um dia de estágio, mais uma aula a ser preparada. Dessa vez, procurei um conteúdo mais leve e descontraído para trabalhar. (...)

(8) Comecei a fazer a correção no quadro porque não estava conseguindo falar, a voz era mínima por motivo de infecção na garganta. Nesse dia a turma estava insuportável, mal educada e sem organização. Estavam totalmente perdidos apesar de terem visto tudo na aula passada e eu não estava a fim de retomar tudo outra vez porque na aula passada quando perguntei se ninguém tinha dúvida, todos falaram que estava tudo bem claro e conseguiram fazer as atividades sozinhos. (...)

Enfim, numa entrada em que a estudante narra a aplicação de uma prova no seu último dia de aula, a impaciência parece ceder lugar ao alívio, mas este não vem sem algum remorso:

(9) Agradeci a todos por terem me suportado durante treze aulas de atuação e pedi desculpas se às vezes eu não contribuí de maneira precisa para uma possível aprendizagem. Todos disseram que foi um prazer ter a minha companhia e que gostariam que eu ficasse ali para sempre como professora. A professora regente deu os parabéns pelo meu desempenho nos estágios, pois acredita que eu peguei uma das turmas mais difíceis de lidar e mesmo assim dei conta do recado. Assim, encerrei meus estágios de atuação no ensino médio.

Permanece coesa a linha de argumentação: mais uma vez surge um elemento que permite redirecionar qualquer crítica a um motivo externo, relacionado a uma imagem negativa da escola: "acredita que eu peguei uma das turmas mais dificeis de lidar". Outro ponto que mereceria algum comentário neste trecho é o recurso de se afirmar a satisfação dos alunos ou dos professores como indicador da qualidade das aulas, embora sem nenhum tipo de documentação além da própria palavra de quem o relata: "todos disseram que foi um prazer ter a minha companhia". Em todo caso, à luz do que vimos levantando, é mais significativo notar que essa declaração é seguida de um suposto pedido cujo teor contradiz a própria postura da estagiária ao agradecer os alunos "por terem me suportado" - eles "gostariam que eu ficasse ali para sempre". A nos pautarmos pela hipótese da identificação da estagiária à imagem que projeta de seus alunos, podemos supor que a relação de papéis no obrigado por terem me suportado pode ser revertida, o que justificaria o pedido de desculpas posterior, mas também o desejo atribuído aos alunos de permanecer eternamente lecionando para aquela turma. Essa espécie de utopia do gozo parece, de fato, vir a calhar, porque fornece uma dose de punição compatível 
com o pedido de desculpas antecedente e contrabalança, finalmente, a inadmissível satisfação do sujeito em não ser bem-sucedido.

\section{Considerações finais}

A leitura desse relatório de estágio teve basicamente dois objetivos que se interlaçam: a) discutir uma situação de ensino que parece passível de certa recorrência, na qual um sujeito, diante da dificuldade de discursivizar parte de sua experiência docente, encontra como única possibilidade de satisfação satisfazer-se com o insucesso, encontrando para tanto um álibi no consenso geral de que a escola, os alunos e os próprios professores estariam sobrecarregados de problemas; e b) demonstrar que há certos aspectos do ensino, fundamentais na perspectiva de uma formação profissional, que só podem ser acessados por uma incursão no terreno da escrita, por meio da ultrapassagem de uma leitura que se retenha no enunciado e pela busca dos testemunhos escritos de um processo de enunciação.

Dentro desse último ponto, busquei analisar de maneira mais detalhada o relatório de estágio e as condições de produção que, num plano imaginário, determinam a forma do produto escrito sobre o qual o professor se debruça. Fundamentalmente, tratou-se de resgatar a opacidade da linguagem, procurando mostrar que o relatório é um enunciado no qual certos elementos não podem ser lidos como se tivessem um valor puramente referencial, porque sua ocorrência se deve antes a uma tentativa de gerenciar os aspectos interacionais e pragmáticos da interlocução entre o estagiário e seu professor. Esses aspectos precisam ser percebidos pelo professor de estágio para que certos movimentos de caráter argumentativo não sejam lidos nem como se fossem dados objetivos, nem como se fossem simples fruto de uma intenção consciente. Pelo contrário, há certos movimentos da escrita que enlaçam, mesmo sob a aparência de argumentos banais, aquelas imagens fundamentais para a constituição de um sujeito. É possível que, para um sujeito, falar em formação seja o mesmo que falar na sua necessidade de passar por essas imagens e elaborar uma solução para os conflitos que elas trazem em que os recursos fornecidos por uma determinada área do saber, na qual ele se especializa, tenham lugar de proeminência.

Resta fazer a ressalva de que, ao contrário do que se pode concluir da análise que empreendemos, um relatório de estágio não é ruim por argumentar, seduzir, conduzir, coagir. Pelo contrário, esses podem ser os maiores índices de sua qualidade, já que atestam a existência de um sujeito disposto a refletir sobre 
os recursos linguísticos que a escrita lhe fornece para realizar um ato sobre o outro. Um relatório é ruim se ele oferecer apenas esse jogo: se não houver nele nada mais que um flerte ou uma ameaça, porque o terreno das trocas possíveis entre o professor e o aluno reduziu-se à estreiteza desse tipo de gesto. Um ponto a partir do qual seria possível começar a construção de uma didática da Licenciatura aberta às problemáticas do sujeito seria o cultivo dos espaços de interlocução por meio da escrita.

\section{Referências}

ALTHUSSER, Louis. Ideologia e aparelhos ideológicos de Estado: notas sobre os aparelhos ideológicos de Estado. São Paulo: Martins Fontes, 1980. 127 p.

GERALDI, João Wanderley. Linguagem e ensino. Exercícios de militância e divulgação. Campinas: ALB/Mercado de Letras, 1996. 150 p.

GINSBURG, Carlo. Sinais. Raízes de um paradigma indiciário. In:

Mitos, emblemas, sinais. Morfologia e história. 2. ed. Trad. Federico Carotti. São Paulo: Companhia das Letras, 1989. p. 143-179.

PÊCHEUX, Michel. Análise automática do discurso (AAD-69). Trad. Eni Pulcinelli Orlandi. In: GADET, Françoise e HAK, Tony (Org.). Por uma análise automática do discurso. Uma introdução à obra de Michel Pêcheux. 3. ed. Campinas: Unicamp, 1997. p. 61-161.

RIOLFI, Claudia et al. Ensino de língua portuguesa. São Paulo: Thomson Learning, 2008. 232 p. (Coleção Ideias em Ação).

Recebido em 23/03/09. Aprovado em 19/06/09. 